\title{
Daily exposure to phthalates and alkylphenols alters miR biogenesis and expression in mice ovaries
}

\author{
Daniel Patiño-García1,2, Leonor Cruz-Fernandes¹, Julio Buñay¹, Renán Orellana² and Ricardo D Moreno¹ \\ 'Departamento de Fisiología, Facultad de Ciencias Biológicas, Pontificia Universidad Católica de Chile (PUC), Santiago, Chile \\ 2Departamento de Ciencias Químicas y Biológicas, Universidad Bernardo O'Higgins, Facultad de Salud, Santiago, Chile
}

Correspondence should be addressed to D Patiño-García: dafpaga@gmail.com

\begin{abstract}
Reproductive hormone imbalance in infertile women is correlated to high levels of phthalates and alkylphenols, which are among endocrine-disrupting chemicals (EDCs). Previous studies have shown that they interfere with gene expression by deregulating levels of microRNAs (miRs), small non-coding RNAs targeting mRNAs encoding enzymes in the hormone biosynthesis pathway. However, this effect depends on the target organ, dose and whether or not they are alone or in mixtures. Our goal was to study whether the biosynthesis, and a specific group of miRs targeting mRNAs encoding enzymes in steroid hormone biosynthesis, are deregulated in the ovaries of female mice chronically exposed to a mixture of three phthalates (DEHP+DBP+BBP) and two alkylphenols $(\mathrm{NP}+\mathrm{OP})$ at a human environmentally relevant dose. We performed GPCR and Western blot assays along with a bioinformatics approach and found that this mixture modified the biogenesis machinery of miRs, inducing an increase in the mRNA levels of Drosha and Dicer1 and DROSHA protein levels. In addition, we found changes in the precursor and mature forms of miR-96-5p, miR-200b-3p, miR-365-3p, miR-378a-3p and miR-503-5p which target steroidogenic pathway enzymes. Finally, using primary granulosa cell culture, we confirmed that miR-200b-3p targets Cyp19a1, transcript encoding CYP19A1, the enzyme that produces estradiol $\left(E_{2}\right)$. These results indicate that chronic exposure to phthalates and alkylphenols mixture alters the biogenesis of ovary miRs and increases the expression of miRs implicated in the control of steroidal hormone synthesis in female mice, thus contributing to reproductive pathologies.
\end{abstract}

\section{Introduction}

Humans are exposed to $\sim 85,000$ different molecules throughout life (Fenner-Crisp et al. 2000), some of which have the property to alter hormone homeostasis and are known as endocrine-disrupting chemicals (EDCs). Phthalates such as bis (2-ethylhexyl) phthalate (DEHP), dibutyl phthalate (DBP), and benzyl butyl phthalate (BBP) are used primarily to soften PVC, and to increase transparency, durability, flexibility and longevity. Alkylphenols such as 4-nonylphenol (NP) and 4-tertoctylphenol (OP) are building blocks in the production of detergents, personal care products, cosmetics, and additives for lubricants, fuels and polymers (Guart et al. 2011, Dodson et al. 2012, Hwang \& Choi 2015, Mitro et al. 2016, Broe et al. 2017). Several evidences indicate that these 
compounds migrate from their containers and enter the body acting as EDCs (Chang et al. 2014, Sathyanarayana et al. 2017). However, most of the toxicological studies on animal models have focused on single compound exposure during a specific developmental window, with high and not environmentally relevant doses; also, in most of them, the method of administration (e.g. intraperitoneal injection) is not related to physiological exposure (Luu et al. 2017, Liu et al. 2018).

In women, these compounds are present in many types of tissues and biological fluids, like the serum, milk, and follicular fluid (Du et al. 2016, 2019, Parikh et al. 2018; https://clinicaltrials.gov/show/NCT01385605), and they are correlated to fertility problems (Tranfo et al. 2012, Du et al. 2016, Messerlian et al. 2016, Parikh et al. 2018, Martinez et al. 2019; https://clinicaltrials.gov/show/ NCT01385605). In addition, in vitro and in vivo murine studies have shown that single and/or mixed exposure to phthalates or alkylphenols influences the development of ovarian follicles and changes gene expression associated with the regulation and synthesis of steroid hormones as well as steroid hormone levels, mainly aromatase (CYP19A1)/ $\mathrm{E}_{2}$ in ovary and testes (Willoughby et al. 2005, Hannon \& Flaws 2015, Bunay et al. 2017, 2018, PatinoGarcia et al. 2018). However, the molecular mechanism by which phthalates and alkylphenols deregulate the expression of steroidogenic pathway enzyme genes has not yet been revealed.

Epigenetic regulation by small non-coding RNAs such as microRNAs (miRs) is a conserved mechanism of post-transcriptional gene expression (Uzumcu et al. 2012, Bunkar et al. 2016). The biogenesis of miRs involves multiple elements and alternative pathways, but four enzymes are considered key factors in the canonical miR pathway. DROSHA and DICER1 are involved in the processing of miRs from pri-miRs (primary miRs), premiRs (miR-precursors) to mature miRs and EXPORTIN-5 (Xpo5), which is implicated in the export of pre-miRs from the nucleus to the cytoplasm, and AGO2 participates in the RNA-induced silencing complex (RISC) that finally binds to target mRNA (Gavin \& Akbarian 2012, GarciaLopez et al. 2013, Bhaskaran \& Mohan 2014). The evidence in mammals shows that miRs regulate follicle development and steroidogenesis in the ovaries (Sang et al. 2013, Li et al. 2015, Toms et al. 2017). Furthermore, gene ablation of Drosha and Dicer1 alters ovary physiology and decreases fecundity (Lykke-Andersen et al. 2008, Nagaraja et al. 2008, Otsuka et al. 2008, Lei et al. 2010, Kuang et al. 2014, Kim et al. 2016, Guo et al. 2017). In women, urinary concentrations of phthalate metabolites are associated with the expression of extracellular vesicle miRs in follicular fluid (Martinez et al. 2019). The exposure to DEHP altered the ovarian miR expression profile of newborn mice (Zhang et al. 2019). In a previous work, we found that female mice chronically exposed to a mixture of phthalates and alkylphenols show a decrease in the expression of ovarian steroidogenesis genes, including CYP19A1, along with a significant decrease in $\mathrm{E}_{2}$ plasmatic levels (Patino-Garcia et al. 2018). We hypothesized that this may be due to alterations in post-transcriptional regulation of genes encoding the steroidogenesis pathway. For this reason, in the present work, our general aim was to study changes in the genes responsible for encoding proteins involved in the biogenesis of miRs as well as in the expression pattern of miRs which act as posttranscriptional regulators of steroidogenic gene expression in mice ovaries exposed to a mixture of phthalates and alkylphenols from conception until adult life.

\section{Materials and methods}

\section{Chemicals}

DEHP, DBP, BBP, NP, OP, and dimethyl sulfoxide (DMSO) were purchased from Sigma-Aldrich. Ethanol was acquired from Winkler (Santiago, Chile). A bulk stock solution containing three phthalates (DEHP, DBP, and BBP) diluted in DMSO and two alkylphenols (NP and OP) diluted in ethanol was used to prepare the final mixture. For vehicle and treatments, the final DMSO and ethanol doses were $2.5 \mathrm{~g} / \mathrm{kg}$-bw/day and $0.06 \mathrm{~g} / \mathrm{kg}$-bw/day. In mice, orally tolerable doses were established at $7.9 \mathrm{~g} / \mathrm{kg}$ for DMSO and $2.5 \mathrm{~g} / \mathrm{kg}$ for ethanol ( $\mathrm{Gad}$ et al. 2016). The mixture dose assayed in this study was $1 \mathrm{mg} / \mathrm{kg}$-bw/day, which was chosen based on the human non-occupational exposure to these compounds (NTP-CERHR 2003a,b, Jonsson 2006, Shelby 2006, Ademollo et al. 2008).

\section{Animals and in vivo dosing regimen}

Adult female C57BL/6J mice aged 60 days were obtained from the Animal Facility of PUC and maintained in bisphenol A-freeH-TEMP polysulfone cages (TECNIPLAST). The mice were housed in an environmentally controlled room under a $12 \mathrm{~h}$ light: $12 \mathrm{~h}$ darkness cycle that was maintained at $22 \pm 1^{\circ} \mathrm{C}$. Phytoestrogen-free food and water were provided for ad libitum consumption. The experimental protocol was approved by the Ethical Scientific Committee for the Care of Animals and the Environment at the PUC No. 141222004. All animal 
protocols were endorsed by the Chilean National Fund of Science and Technology (FONDECYT).

The mixture used in the present study represents the most abundant phthalates and alkylphenols in everyday products (Snedeker \& Hay 2014, Mitro et al. 2016). Doses were chosen based on non-occupational exposure to these compounds $(0.3 \mathrm{mg} / \mathrm{kg}$-bw/day for each phthalate and $0.05 \mathrm{mg} / \mathrm{kg}$-bw/day for each alkylphenol) (FDA 2001, Kavlock et al. 2002, Jonsson 2006, Kavlock et al. 2006, Hines et al. 2011, Mitro et al. 2016, Somasundaram et al. 2017). In this way, we generated the dose of this mixture resembling non-occupational ( $1 \mathrm{mg} / \mathrm{kg}$-bw/day) human exposure. It should be noted that these doses are, in relation to NOAEL and LOAEL of DEHP and NP, $\approx 1000$ times lower for endocrine-reproductive adverse effects in humans, rats and mice (Chapin et al. 1999, ATSDR 2002, Osimitz et al. 2015) which made human-relevant doses.

The final dose was calculated according to the body weight and volume of water ingested by the mice recorded in a pilot study and in agreement with data in the literature referring to these parameters (Bachmanov et al. 2002, Spangenberg et al. 2014). Water intake was controlled each day. The global water intake was not affected by exposure to the phthalates and alkylphenols mixture or vehicle. The mixture of phthalates and alkylphenols was freshly made according to the changes in animal body weight (bw) and administered in the drinking water and throughout the experimental period. The bottle was covered with foil to prevent photolysis of the compounds.

To emulate chronic human exposure to an environmental mixture of phthalates and alkylphenols, we administered the mixture $(1 \mathrm{mg} / \mathrm{kg} /$ day; containing $0.3 \mathrm{mg} / \mathrm{kg}$-bw/day of each phthalate (DEHP, DBP and BBP) and $0.05 \mathrm{mg} / \mathrm{kg}$-bw/day of each alkylphenol (NP and OP)) or vehicle (control: DMSO and ethanol) to pregnant mice from day 0.5 post-coitus (biological $n$ ) during pregnancy and lactation as described above (Table 1). At weaning (day 21), only females were selected and maintained in a group of three to four individuals per cage. We continued the administration of the mixture of phthalates and alkylphenols or control until adulthood. At the end of the treatment, females (60 days old) in estrous were killed, and both ovaries were aseptically removed and; cleaned of interstitial tissue.

\section{RNA extraction and real-time polymerase chain reaction}

Total RNA was extracted from the ovary samples using TRIzol reagent (Invitrogen). The quantity and integrity of total RNA were determined by a Thermo Scientific Nanodrop 2000 spectrophotometer. Gene and primaryprecursor (pri-pre-miR) cDNA was synthesized from $1 \mu \mathrm{g}$ RNA by RT Master Mix (Promega) and random primers. The cDNA of miRs was synthesized using a previously described protocol (Cirera \& Busk 2014). Briefly, $100 \mathrm{ng}$ of total RNA was poly(A)-tailed and reverse-transcribed in a single reaction tube containing $0.1 \mathrm{mM}$ of ATP, $0.1 \mathrm{mM}$ of dNTPs, 100 units of MMLV reverse transcriptase (New England Biolabs), $1 \mu \mathrm{L}$ of $10 \mathrm{x}$ poly(A) polymerase buffer, 1 unit of poly(A) polymerase (New England Biolabs) and $1 \mu \mathrm{M}$ of Oligo (dT) Adaptor (Applied Biological Materials, Richmond, Canada) in a final volume of $10 \mu \mathrm{L}$. The qPCR was performed using $1 \mu \mathrm{M}$ of primers and 2XSyBR Green Fast qPCR MasterMix (Biotool, TX, USA). Expression data were normalized using the $2^{\Delta \Delta \mathrm{Ct}}$ method with Gapdh and $A c t b$ as endogenous reference genes for mRNAs and U6 snRNA for miRs. Primers for miR-200b-3p (MPM00977) and miR-503-5p (MPM01369) were obtained from Applied Biological Materials. The miRprimer (Busk 2014) software was used to design functional forward primers for the miR-96-5p, miR-365-3p and miR-378a-3p. Both mRNAs and specific miR forward primers (Table 2), and the 3' universal primer (Applied Biological Materials) were used for endogenous miR analysis.

Table 1 Body weight and water consumption by the mice dam.

\begin{tabular}{|c|c|c|c|c|}
\hline \multirow[b]{2}{*}{ Variables } & \multicolumn{4}{|c|}{ Gestational and lactation stages } \\
\hline & Beginning of pregnancy & Mid pregnancy & End of pregnancy & Lactation \\
\hline \multicolumn{5}{|c|}{ Body weight (g) } \\
\hline Vehicle & $18.5 \pm 0.43$ & $25.6 \pm 1.46$ & $35.0 \pm 1.00$ & $26.1 \pm 0.40$ \\
\hline EDCs & $18.6 \pm 0.37$ & $25.4 \pm 1.42$ & $33.5 \pm 1.19$ & $24.6 \pm 0.56$ \\
\hline \multicolumn{5}{|c|}{ Water intake (mL) } \\
\hline Vehicle & $4.6 \pm 0.06$ & $6.4 \pm 0.23$ & $8.8 \pm 0.30$ & $23.1 \pm 2.33$ \\
\hline EDCs & $4.7 \pm 0.09$ & $6.6 \pm 0.13$ & $8.4 \pm 0.34$ & $22.1 \pm 1.78$ \\
\hline
\end{tabular}

Values represent the mean \pm S.E.M., $n=4$. No differences were observed to compare vehicle and EDCS.

EDCs (mixture of phthalates and alkylphenols). 


\section{Protein extraction and Western blotting}

Protein extraction and Western blotting were performed as previously published (Patino-Garcia et al. 2019). Briefly, the homogenization of ovaries was performed in a buffer containing $1 \mathrm{M} \mathrm{NaCl}, 1 \mathrm{mM}$ EDTA, $10 \mathrm{mg} / \mathrm{mL}$ PMSF, 1\% Triton $\mathrm{X}-100$, and $20 \mathrm{mM}$ Tris- $\mathrm{HCl} \mathrm{pH} 7.4$, plus a general metalloprotease inhibitor, BB-94 $10 \mu \mathrm{M}$, and protease inhibitor cocktail (Sigma), and then centrifuged for $10 \mathrm{~min}$ at $10,000 \boldsymbol{g}$ at $4^{\circ} \mathrm{C}$. Then, samples of $20 \mu \mathrm{g}$ of protein were separated by electrophoresis on a $10 \%$ polyacrylamide gel (SDS-PAGE) under denaturing and reducing conditions before being transferred to a nitrocellulose membrane (Thermo Scientific) at $350 \mathrm{~mA}$ for $2 \mathrm{~h}$. Next, membranes were incubated with sodium citrate solution $0.01 \mathrm{M}$, $\mathrm{pH} 6.0$, for $10 \mathrm{~min}$ at $95^{\circ} \mathrm{C}$ to expose the antigens and blocked with a solution of 3\% (w/v) BSA $0.1 \%(\mathrm{v} / \mathrm{v})$ Tween in Tris-buffered saline, $\mathrm{pH} 7.4$ and incubated overnight with the respective primary antibodies for DROSHA (1:1000) (Santa Cruz Biotechnology) and ACTB (1:5000)
(Abbexa, Cambridge, UK) as a loading control. Finally, the second incubation took place with their respective secondary antibodies conjugated with horseradish peroxidase (KPL, Gaithersburg, MD, USA) diluted 1:5000 in blocking solution for $1 \mathrm{~h}$ at room temperature. Peroxidase activity was detected using the Western Lightning Chemiluminescence Reagent Plus kit (PerkinElmer).

\section{Bioinformatics analyses}

Predicted miR targets for steroidogenic mRNAs were obtained using the searches of several databases that including miRWalk, miRecords and MicroCosm. To filter the large number of obtained miRs, presence in the ovary was determined using mimiRNA. Also, to verify whether miR levels were affected by some of the compounds evaluated in this work, we used ChemiRs. Finally, validated mRNA targets for certain miRs were obtained using the miRWalk database and DIANA-TarBase v7.0. Validated miR-mRNA target interactions were performed using the

Table 2 Sequence of qPCR primers.

Name
Drosha
Xpo5
Dicer1
Ago2
Pri-pre-let-7f
Pri-pre-miR-96
Pri-pre-miR-200b
mi-pre-miR-203
miR-378a-3p
U6
Pri-pre-miR-221
Pri-pre-miR-365
Pri-pre-miR-378a

\section{Primer}

Forward primer

Reverse primer

Forward primer

Reverse primer

Forward primer

Reverse primer

Forward primer

Reverse primer

Forward primer

Reverse primer

Forward primer

Reverse primer

Forward primer

Reverse primer

Forward primer

Reverse primer

Forward primer

Reverse primer

Forward primer

Reverse primer

Forward primer

Reverse primer

Forward primer

Reverse primer

Forward primer

Reverse primer

Forward primer

Reverse primer

Forward primer

Forward primer

Forward primer

Forward primer

Reverse primer
Sequence $\left(5^{\prime}-3^{\prime}\right)$

GGACCATCACGAAGGACACTT

ATGCCCAGTTCCTCTGCTACCT

GAAGTAGCCCCCTCGTCTGT

AGCAGTGCTGTGCAGACATC

GGATGCGATGTGCTATCTGGA

GCACTGCTCCGTGTGCAA

GCCGTCCTTCCCACTACCAC

GGTATTGACACAGAGCGTGTGC

GATTGTATAGTTGTGGGGTAGTGA

TCAGGGAAGGCAATAGATTGTA

CCGATTTTGGCACTAGCAC

CATATTGGCATGCACATGA

CCGTGGCCATCTTACTGG

TCCGCCGTCATCATTACC

GCTGGGTCCAGTGGTTCTTA

GCCGGGTCTAGTGGTCCTA

CACCATCCAGGTCTGGGG

TTCCAGGTAGCCTGAAACCC

TCACCTCGGCTCATCTGG

TGACCTTCCTTGGGCACT

AGGGCTCCTGACTCCAGG

AGGCCTTCTGACTCCAAGTC

GCCAGATCTTTTGCCCTATTCCTTGCC

GCCGAATTCTCTGATTGGGAAGGGATTTT

GCTGATGCTCCCATGTTCGTGAT

GTGGTGCAAGAGGCATTGCTGAC

GCTTCTTTGCAGCTCCTTCGT

CCAGCGCAGCGATATCG

TTTGGCACTAGCACATTTTTGCT

TAATGCCCCTAAAAATCCTTAT

ACTGGACTTGGAGTCAGAAGG

CGCTTCGGCAGCACATATAC

AAAATATGGAACGCTTCACGA 
Cytoscape software. Functional analysis for potential mRNA targets in biological processes of gene ontology (GO) domains was performed using a Cytoscape plugging ClueGO.

\section{Statistical analysis}

All data represent the mean \pm s.E.M. We analyzed the differences in the averages through the unpaired $t$-test and the Mann-Whitney $U$-test or one-way ANOVA along with Tukey's post hoc test using GraphPad Prism version 5.0 (GraphPad Software); $P$ values $<0.05$ were considered statistically significant. Heatmap was performed using QCanvas 1.2.1. GO enrichment analysis was carried out using a hypergeometric test with a $P$ value less than 0.05 and Kappa score of 1.

\section{Results}

Phthalate and alkylphenol mixtures changed the expression levels of genes involved in the biogenesis of miRs

Since exposure to phthalates and alkylphenols affects the biogenesis machinery of miRs in the testes (Bunay et al. 2017,2019 ), we wondered if this also occurred in the ovaries of females under the same experimental conditions. To answer this question, we quantified the mRNA expression levels of genes encoding for Drosha, Dicer1, Ago2 and Xpo5, along with DROSHA protein levels. We found significantly increased levels of Drosha and Dicer1 mRNA and DROSHA protein in the ovaries of exposed mice (Fig. 1). However, mRNA levels of Xpo5 and Ago2 were similar to those of control mice (Fig. 1A). Thus, some elements of the machinery for biogenesis are upregulated by exposure to phthalates and alkylphenols mixture in ovaries, which might explain the change in the miR global profile.

\section{The exposure to phthalates and alkylphenols mixture alters pri-pre-miRs}

The next step was to determine whether exposure to the phthalates and alkylphenols mixture impaired primary-precursor (pri-pre-miR) levels to mature miRs targeting mRNAs encoding enzymes in steroid hormone biosynthesis. First, we aimed to identify predicted miRs that target Star and Cyp19a1, given that this mixture
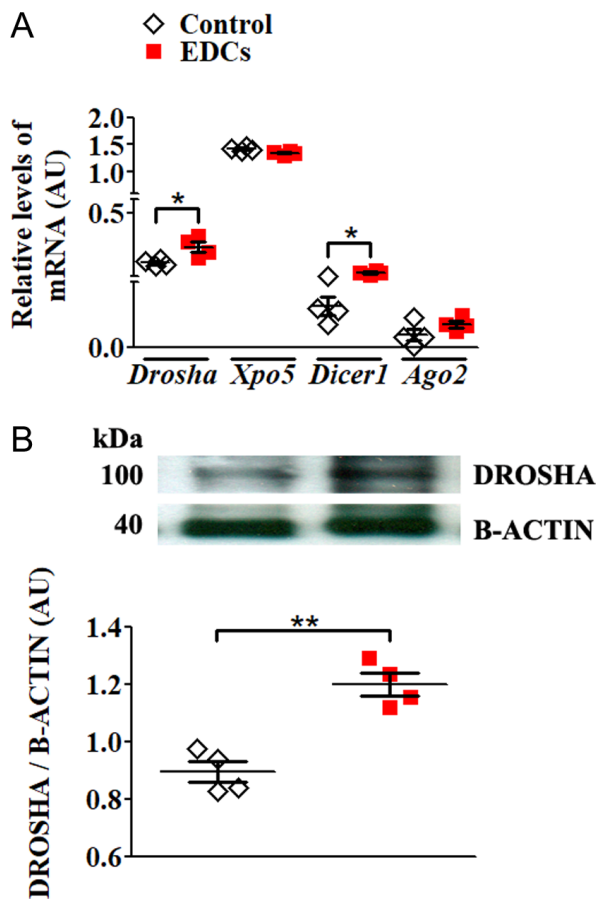

\section{Figure 1}

Exposure to the mixture of phthalates and alkylphenols induces changes in the miR biogenesis machinery. (A) RT-qPCR analysis of mRNA levels of genes that encode proteins involved in miR biogenesis and miR nuclear export and editing. (B) DROSHA protein levels. Values represent the mean \pm S.E.M., Mann-Whitney U-test, $n=4$ (each data point represents one animal), $* P<0.05, * \star P<0.01$. EDCs (mixture of phthalates and alkylphenols), and AU (arbitrary units). A full color version of this figure is available at https://doi.org/10.1530/JME-20-0149.

of compounds decreased the mRNA levels of those transcripts in our previous study (Patino-Garcia et al. 2018). During in silico analysis, we detected that nine mature miRs would potentially target Star (mmumiR-96-5p, mmu-miR-365-3pandmmu-miR-378a-5p), and Cyp19a1 (mmu-let-7f-1-3p, mmu-miR-200b-3p, mmumiR-203-3p, mmu-miR-221-5p, mmu-miR-365-3p, mmumiR-378a-3p and mmu-miR-503-5p). The evaluation of pri-pre-miR levels in the ovaries of exposed females showed a decrease in the levels of pri-pre-miRs for mmulet-7f-1-3p, mmu-miR-203-3p and mmu-miR-221-5p. On the other hand, we found an increase in the levels of pri-pre-miRs of mmu-miR-96-5p, mmu-miR-200b-3p, mmu-miR-365-3p, mmu-miR-378a-3p, mmu-miR-378a-5p, and mmu-miR-503-5p (Fig. 2A). Next, we validated the increase in these pri-pre-miRs by quantifying their mature miRs. The results showed that levels of the mature forms of all five upregulated pri-pre-miRs were also increased compared to control-treated mice (Fig. 2B). 
A
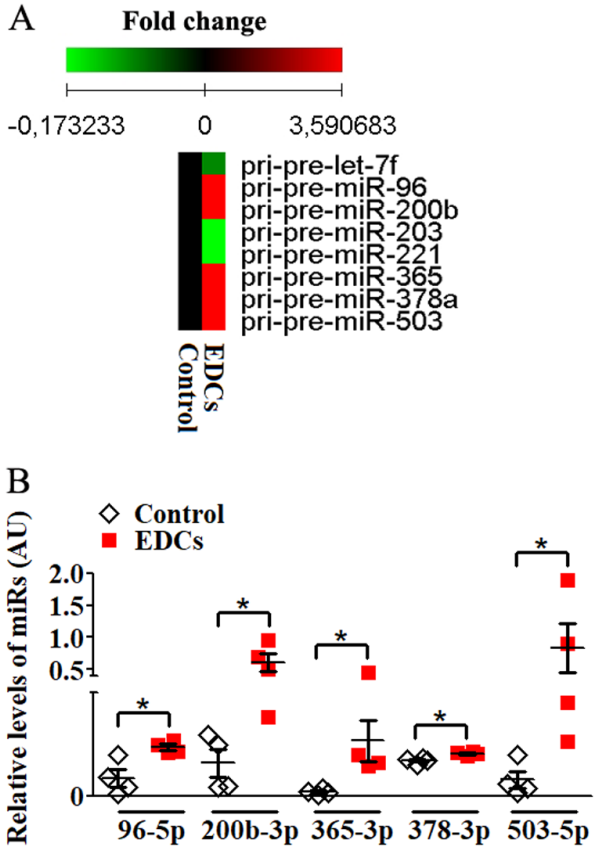

\section{Figure 2}

Exposure to the mixture of phthalates and alkylphenols alters precursor and mature miRs. RT-qPCR analysis of (A) pri-pre-miRs and (B) miRs. Heat map of the 8 pri-pre-miRs in female mice ovaries following EDCs treatment. The differential expression of pri-pre-miRs can be easily followed by a color-coded approach, indicating low levels of pri-pre-miR content with green, and high levels with red. The data for pri-pre-miRs are presented as fold change with respect to control. Values represent the mean \pm S.E.M., Mann-Whitney $U$-test, $n=4$ (each data point represents one animal), $* P<0.05$. EDCs (mixture of phthalates and alkylphenols) and AU (arbitrary units). A full color version of this figure is available at https:// doi.org/10.1530/JME-20-0149.

\section{The exposure to phthalates and alkylphenols mixture alters the miR levels in ovary of adult females}

Given that the upregulation of miRs is involved in the post-transcriptional control (mostly repression) of target mRNAs, we developed an integrative in silico analysis of validated miR-mRNA target interactions. This analysis revealed that three out of five upregulated miRs (miR-200b-3p, miR-378a-3p and miR-503-5p) are involved in the down-regulation of a set of genes related to steroidogenic pathways (Fig. 3A), affecting reproductive processes such as the regulation of folliclestimulating hormone secretion, follicle and uterus development, estrogen receptor signaling and response to gonadotropin (Fig. 3B).

Of the three miRs targeting the Cyp19a1 mRNA (miR-378a-3p, miR-503-5p and miR-200b-3p), we chose to study miR-200b-3p because it is increased in women with PCOS (Xue et al. 2018, He et al. 2019) and the other two have
A

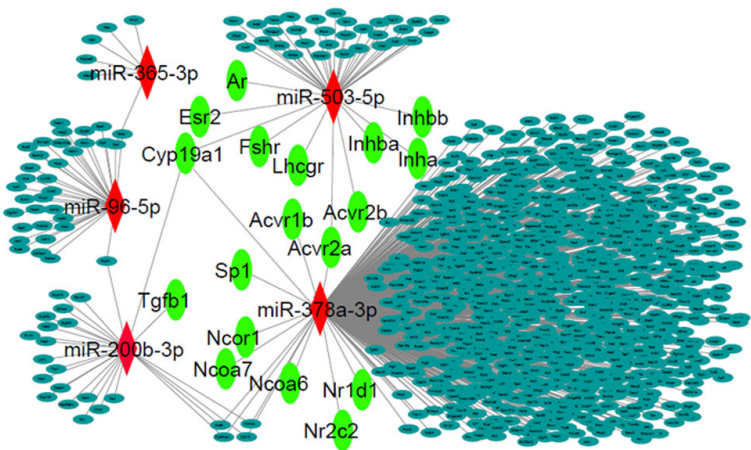

B

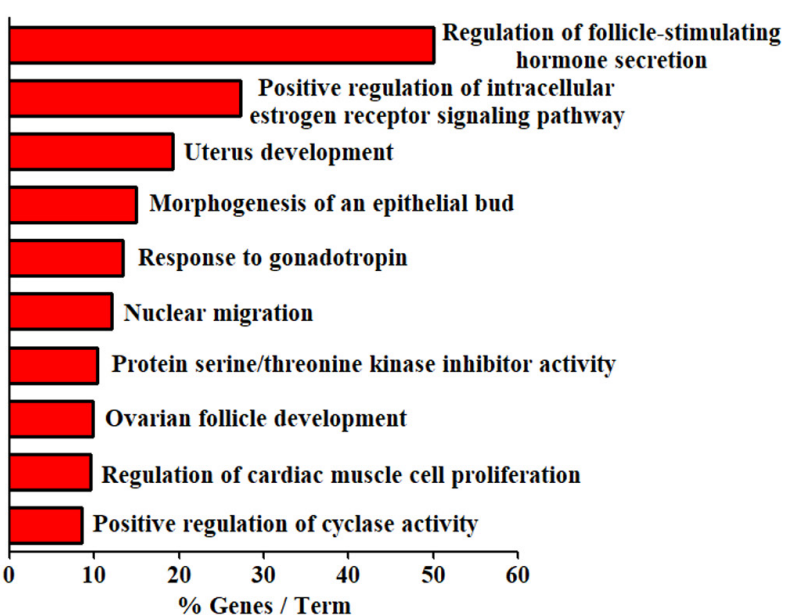

Figure 3

Gene ontology (GO) enrichment analysis of genes targeted by upregulated miRs. The miRs that are upregulated in mice ovaries after exposure to mixture of EDCs are shown in red rhombuses and its validated target genes are shown in green ovals (A). Enrichment analysis of downregulated genes (B). GO enrichment analysis was carried using a hypergeometric test with a $P$-value less than 0.05 and Kappa score of 1 . A full color version of this figure is available at https://doi.org/10.1530/JME-20-0149.

already been experimentally validated to target Cyp19A1 mRNA (Lei et al. 2010, Xu et al. 2011, Pan et al. 2015). First, we reconfirmed the predicted results for Cyp19a1 as a target of miR-200b-3p using the online tool, FindTar3 (Ye et al. 2008), which offers a qualitative assessment for miR-mRNA binding and was rated 'excellent' for the mouse and 'good' for the human gene (Fig. 4A). In order to experimentally validate the in silico results, we used a primary cell culture from mouse granulosa cells, which are the somatic cells surrounding the oocyte and produce and secrete $\mathrm{E}_{2}$. The results showed a significant decrease in $\mathrm{E}_{2}$ secretion as well as mRNA and protein levels of CYP19A1, when cells were transfected with agomiR-200b-3p, which mimics the action of endogenous miR-200b-3p (Fig. 4B, C and D). On the other hand, only protein levels of CYP19A1 increased when granulosa cells were transfected with the antagomiR-200b-3p (Fig. 4D), which antagonize the action 


\begin{tabular}{|c|c|c|c|c|c|c|}
\hline miRNA & mRNA & Position & Structure & Loop Score & $\Delta \mathrm{G}$ & Recommendation \\
\hline$m m u-m i R-200 b-3 p$ & NM_007810 & 716-737 & 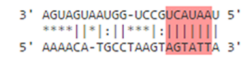 & 25.00 & -18.10 & excellent \\
\hline miRNA & mRNA & Position & Structure & Loop Score & $\Delta G$ & Recommendation \\
\hline hsa-miR-200b-3p & NM_000103 & $738-763$ & 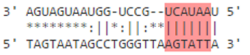 & 15.00 & -16.40 & good \\
\hline
\end{tabular}

B
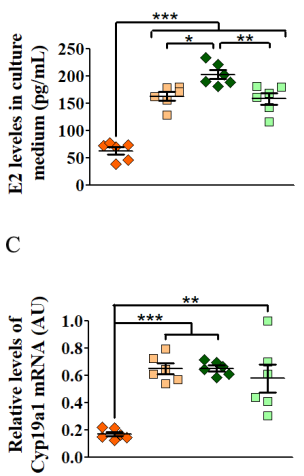

D

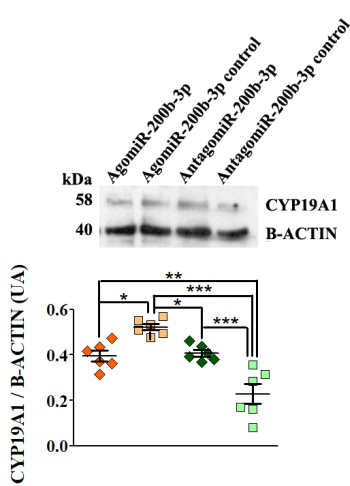

AgomiR-200b-3p A AntagomiR-200b-3p of endogenous miR-200b-3p (Fig. 4E). Further data confirm the increase or decrease miR-200b-3p levels after treatment with agomiR or antagomiR, respectively (Fig. 4E). Therefore, these in vitro results strongly suggest that miR-200b-3p targets Cyp19a1 mRNA in mouse granulosa cells.

Overall, these data suggest that the dysregulation of the biosynthetic machinery of miRs and levels of miRs targeting mRNAs encoding steroidogenic enzymes, in the ovary of females treated with a mixture of phthalates and alkylphenols, is a mechanism that underlies their endocrine-disrupting action.

\section{Discussion}

Recent evidence shows that changes in reproductive tissue function due to exposure to environmental EDCs, such as bisphenol A (Lin et al. 2017) or DBP (Gaido et al. 2007), could be explained by the disruption in the posttranscriptional regulatory machinery, where a pivotal step is the mRNA stability regulated by miRs. Here, we show that chronic exposure to a mixture of three phthalates and two alkylphenols, from conception to adulthood, induces the upregulation of Drosha and Dicer1 in the ovary of exposed female mice, suggesting a possible disruption mechanism in the processing of miRs that may explain the changes at the endocrine and reproductive level (Patino-Garcia et al. 2018).

Selective inactivation of Dicer1 in prophase I oocytes of the fetal ovary led to compromised folliculogenesis, premature ovarian failure and infertility in adult mice

\section{Figure 4}

The miR-200b-3p suppresses $E_{2}$ production and CYP19A1 protein levels in mice granulosa cells. Online prediction software predicted relationship between miR-200b-3p and Cyp19a1 in mice (top) and human (bottom) (A). Levels of $E_{2}$ in culture medium collected from granulosa cells transfected with miR-200b-3p. RT-qPCR of Cyp19a1 in granulosa cells transfected with miR-200b-3p (C). CYP19A1 protein levels after miR-200b-3p transfection (D), and miR-200b-3p transfection control (E). Values represent the mean \pm s.E.M., Mann-Whitney U-test, $n=3$ with two technical replicates each, $* P<0.05$, $\star \star P<0.01, * \star * P<0.001$. EDCs (mixture of phthalates and alkylphenols), AU (arbitrary units), and $\mathrm{E}_{2}$ (estradiol). A full color version of this figure is available at https://doi.org/10.1530/ JME-20-0149.
(Yuan et al. 2014). Therefore, the analysis of Drosha and Dicer1 in infertile women would also provide further clues about the genetic etiology underlying premature ovarian failure and infertility during EDCs exposure, such as phthalates and alkylphenols.

Previous studies have shown that some elements of the canonical biogenesis machinery, like Drosha and Dicer 1 are dysregulated by single EDCs, xenobiotics and/or environmental chemicals in vitro or in vivo. For example, the expression of Drosha mRNA was decreased by BPA (Tait et al. 2015, Lin et al. 2017, Mahemuti et al. 2018); and it was increased by dioxin/ethinyl (Boverhof et al. 2008), flutamide (Laifenfeld et al. 2014), titanium dioxide (Jennen et al. 2010) and dicrotophos (an organophosphate insecticide) (Hseu et al. 2017). In the same way, Dicer1 mRNA expression was decreased by benzo(a)pyrene (Jennen et al. 2010, Magkoufopoulou et al. 2011), BPA (Ali et al. 2014), ochratoxin A (a mycotoxin) (Qi et al. 2014) and DBP (Gaido et al. 2007). Interestingly, our previous study in testes from mice exposed to the same mixture, and under the same conditions as those described in this work, show an increase in Drosha but no change in the levels of Dicer1, Ago2 or Exportin-5, suggesting some similarities and differences between the sexes (Bunay et al. 2017). In this way, the regulation of miR expression by the biogenesis enzymes such as DROSHA, DICER1 and others (e.g. TUT4-7 and LIN28B) would be more than a general mechanism, a selective mechanism which also involves the decay and degradation of other miRs (Kim et al. 2015, Bunay et al. 2017). 
Drosha and Dicer 1 are transcriptionally regulated by different pathways. One of the most relevant is c-Myc, a transcription factor that directly transactivates Drosha mRNA (Wang et al. 2013) and possibly also Dicer1 mRNA through E2F/c-Myc loop (Fernandez et al. 2003, Leung et al. 2008, Blandino et al. 2012). In this way, it has been reported that DBP and NP, two molecules of our mixture, increase c-Myc mRNA levels (Kostka et al. 2010, Lü et al. 2010). On the other hand, the transcriptional regulation of Dicer1 is complex, due to many factor cell-, tissueor stage-specific factors (Kurzynska-Kokorniak et al. 2015), and where ADAR1 and TUT4, two Dicer1-positive regulators, are increased by phthalates and alkylphenols mixture in male mice (Bunay et al. 2017).

Some works show that altered ovary phenotypes after a single exposure to phthalates (DEHP and DBP) or alkylphenols as BPA correlate with global changes in the transcriptome (Lawson et al. 2011, Li et al. 2016, Liu et al. 2018). New research has proposed a link between these changes in mRNA expression and the loss of the post-transcriptional regulation by miRs or other sncRNAs (Sandhu et al. 2012) affecting female fertility (Ahmed et al. 2017, Lite et al. 2019). Studying the miRome (miR expression) profile, Zhang et al. showed that only some miRs were deregulated and the progesterone-mediated oocyte maturation signaling pathway was one of the most altered in newborn mice ovaries after exposure to DBP (Zhang et al. 2019). Interestingly, mmu-miR-200a-5p was reported to be upregulated. This $\mathrm{miR}$ is part of the miR-200 family, which includes miR-200b (Senfter et al. 2016), and was implicated in ovarian development, folliculogenesis and female fertility (Ahn et al. 2010, Zou et al. 2020). Here, we report an increase in both the precursors and mature miRs (miR-96-5p, miR-200b-3p, miR-365-3p, miR-378a-3p and miR-503-5p) giving an account of the relationship of miR expression between pre- and mature forms (Donadeu et al. 2017). In addition, predicted miRs that target Star and Cyp19a1 increased while the target transcripts decreased (Patino-Garcia et al. 2018). Interestingly, in silico analysis revealed that three upregulated miRs (miR-200b-3p, miR-378a-3p and miR-503-5p) target a set of mRNAs encoding proteins related to the steroidogenic pathway and ovarian follicle development. Among their targets are Lhcgr, Fshr, Ar, Esr1, Esr2, Igf1, Tgfb1, Cyp19a1, Inha and Acvr2 which are critical for steroid biosynthesis, the steroid signaling pathway, progression from pre-antral to antral follicles and pre-ovulatory follicle development (Thomas et al. 2003, Drummond 2006, Young \& McNeilly 2010, Gleicher et al. 2011, Sanchez \& Smitz 2012, Wood \& Rajkovic 2013, Nayak et al. 2016).
Here, we use in silico analysis to show that three miRs (miR-200b-3p, miR-378a-3p and miR-503-5p) expressed in mice and human ovaries target the mRNA of Cyp19a1, the enzyme that produces $\mathrm{E}_{2}$ from testosterone (Liang et al. 2007, Ahn et al. 2010). In addition, miR-503-5p is expressed at low levels during ovarian folliculogenesis (McBride et al. 2012) in the cytoplasm of granulosa cells (Lei et al. 2010). By contrast, miR-378a-3p presents higher expression levels in granulosa but no theca cells from atretic follicles (Donadeu et al. 2017). Recent studies have shown upregulated levels of miR-200b-3p in both the blood and follicular fluid of anovulatory women (Huang et al. 2016, Eisenberg et al. 2017, Xue et al. 2018). Here, we experimentally validate that in vitro miR-200b-3p targets Cyp19a1 mRNA, suggesting that this could be a mechanism in vivo by which exposure to phthalate and alkylphenol mixtures could downregulated the levels of $\mathrm{E}_{2}$ and contribute to the observed effects in follicle progression disruption and imbalances in hormone levels. Likewise, the downregulation of miR-145a-5p in neonatal mouse ovary culture increases the expression of TGFBR2, inducing activation of the TGFB signaling pathway, which is important for primordial to primary follicle transition (Yang et al. 2013). Thus, the overexpression of miR-200b-3p, miR-378a-3p and miR-503-5p could alter the pre-antral to antral follicle progression through the repression or degradation of steroidogenic transcripts such as Cyp19a1 by phthalate and alkylphenol exposure, compromising female fertility.

In conclusion, these findings add evidence to the emerging role of miRs in the effect of exposure to phthalates and alkylphenols in a non-occupational manner. We identify a putative upregulation mechanism of certain miRs involved in phthalates and alkylphenols mixture-induced hormone disruption (mainly estradiol) and ovarian dysregulation. Validates analysis suggested dysregulation of the steroidogenesis signaling pathway and reproductive processes. Overall, these data laid the foundation for further investigations into the use of miRs as markers of ovarian insult by phthalates and alkylphenols mixtures exposure.

\section{Declaration of interest}

The authors declare that there is no conflict of interest that could be perceived as prejudicing the impartiality of the research reported.

\section{Funding}

This work was supported by grants from FONDECYT (Grants 1150352 to R D M, 11170603 to R O, and 3200591 to D P-G). 


\section{References}

Ademollo N, Ferrara F, Delise M, Fabietti F \& Funari E 2008 Nonylphenol and octylphenol in human breast milk. Environment International $\mathbf{3 4}$ 984-987. (https://doi.org/10.1016/j.envint.2008.03.001)

Ahmed K, LaPierre MP, Gasser E, Denzler R, Yang Y, Rulicke T, Kero J, Latreille M \& Stoffel M 2017 Loss of microRNA-7a2 induces hypogonadotropic hypogonadism and infertility. Journal of Clinical Investigation 127 1061-1074. (https://doi.org/10.1172/JCI90031)

Ahn HW, Morin RD, Zhao H, Harris RA, Coarfa C, Chen ZJ, Milosavljevic A, Marra MA \& Rajkovic A 2010 MicroRNA transcriptome in the newborn mouse ovaries determined by massive parallel sequencing. Molecular Human Reproduction 16 463-471. (https://doi.org/10.1093/molehr/gaq017)

Ali S, Steinmetz G, Montillet G, Perrard MH, Loundou A, Durand P, Guichaoua MR \& Prat O 2014 Exposure to low-dose bisphenol A impairs meiosis in the rat seminiferous tubule culture model: a physiotoxicogenomic approach. PLOS ONE 9 e106245. (https://doi. org/10.1371/journal.pone.0106245)

ATSDR 2002 Toxicological Profile for Di(2-Ethylhexyl)Phthalate. Atlanta GA, USA: United States Department of Health and Human Services, Public Health Service. (available at: https://www.atsdr.cdc.gov/ toxprofiles $/$ tp. asp? $\mathrm{id}=684 \& \mathrm{tid}=65$ )

Bachmanov AA, Reed DR, Beauchamp GK \& Tordoff MG 2002 Food intake, water intake, and rinking spout side preference of 28 mouse strains. Behavior Genetics 32 435-443. (https://doi. org/10.1023/a:1020884312053)

Bhaskaran M \& Mohan M 2014 MicroRNAs: history, biogenesis, and their evolving role in animal development and disease. Veterinary Pathology 51 759-774. (https://doi.org/10.1177/0300985813502820)

Blandino G, Valerio M, Cioce M, Mori F, Casadei L, Pulito C, Sacconi A, Biagioni F, Cortese G, Galanti S, et al. 2012 Metformin elicits anticancer effects through the sequential modulation of DICER and c-MYC. Nature Communications 3 865. (https://doi.org/10.1038/ncomms1859)

Boverhof DR, Burgoon LD, Williams KJ \& Zacharewski TR 2008 Inhibition of estrogen-mediated uterine gene expression responses by dioxin. Molecular Pharmacology 73 82-93. (https://doi. org $/ 10.1124 / \mathrm{mol} .107 .040451)$

Broe A, Ennis ZN, Pottegard A, Hallas J, Ahern T \& Damkier P 2017 Population exposure to phthalate-containing drugs. Basic and Clinical Pharmacology and Toxicology 121 153-158. (https://doi. org/10.1111/bcpt.12781)

Bunay J, Larriba E, Moreno RD \& Del Mazo J 2017 Chronic low-dose exposure to a mixture of environmental endocrine disruptors induces microRNAs/isomiRs deregulation in mouse concomitant with intratesticular estradiol reduction. Scientific Reports 73373. (https://doi.org/10.1038/s41598-017-02752-7)

Bunay J, Larriba E, Patino-Garcia D, Cruz-Fernanes L, CastanedaZegarra S, Rodriguez-Fernandez M, Del Mazo J \& Moreno RD 2018 Editor's highlight: differential effects of exposure to single versus a mixture of endocrine-disrupting chemicals on steroidogenesis pathway in mouse testes. Toxicological Sciences 161 76-86. (https:// doi.org/10.1093/toxsci/kfx200)

Bunay J, Larriba E, Patino-Garcia D, Urriola-Munoz P, Moreno RD \& Del Mazo J 2019 Combined proteomic and miRNome analyses of mouse testis exposed to an endocrine disruptors chemicals mixture reveals altered toxicological pathways involved in male infertility. Molecular Human Reproduction 25 156-169. (https://doi.org/10.1093/molehr/ gaz003)

Bunkar N, Pathak N, Lohiya NK \& Mishra PK 2016 Epigenetics: a key paradigm in reproductive health. Clinical and Experimental Reproductive Medicine 43 59-81. (https://doi.org/10.5653/ cerm.2016.43.2.59)

Busk PK 2014 A tool for design of primers for microRNA-specific quantitative RT-qPCR. BMC Bioinformatics 15 29. (https://doi. org/10.1186/1471-2105-15-29)
Chang CH, Tsai MS, Lin CL, Hou JW, Wang TH, Tsai YA, Liao KW, Mao IF \& Chen ML 2014 The association between nonylphenols and sexual hormones levels among pregnant women: a cohort study in Taiwan. PLOS ONE 9 e104245. (https://doi.org/10.1371/journal. pone.0104245)

Chapin RE, Delaney J, Wang Y, Lanning L, Davis B, Collins B, Mintz N \& Wolfe G 1999 The effects of 4-nonylphenol in rats: a multigeneration reproduction study. Toxicological Sciences 52 80-91. (https://doi.org/10.1093/toxsci/52.1.80)

Cirera S \& Busk PK 2014 Quantification of miRNAs by a simple and specific qPCR method. Methods in Molecular Biology 1182 73-81. (https://doi.org/10.1007/978-1-4939-1062-5_7)

Dodson RE, Nishioka M, Standley LJ, Perovich LJ, Brody JG \& Rudel RA 2012 Endocrine disruptors and asthma-associated chemicals in consumer products. Environmental Health Perspectives 120 935-943. (https://doi.org/10.1289/ehp.1104052)

Donadeu FX, Mohammed BT \& Ioannidis J 2017 A miRNA target network putatively involved in follicular atresia. Domestic Animal Endocrinology 58 76-83. (https://doi.org/10.1016/j. domaniend.2016.08.002)

Drummond AE 2006 The role of steroids in follicular growth. Reproductive Biology and Endocrinology 4 16. (https://doi. org/10.1186/1477-7827-4-16)

Du Y, Guo N, Wang Y, Teng X, Hua X, Deng T, Yao Y, Yuan X \& Li Y 2019 Follicular fluid concentrations of phthalate metabolites are associated with altered intrafollicular reproductive hormones in women undergoing in vitro fertilization. Fertility and Sterility $\mathbf{1 1 1}$ 953-961. (https://doi.org/10.1016/j.fertnstert.2019.01.021)

Du YY, Fang YL, Wang YX, Zeng Q, Guo N, Zhao H \& Li YF 2016 Follicular fluid and urinary concentrations of phthalate metabolites among infertile women and associations with in vitro fertilization parameters. Reproductive Toxicology 61 142-150. (https://doi. org/10.1016/j.reprotox.2016.04.005)

Eisenberg I, Nahmias N, Novoselsky Persky M, Greenfield C, Goldman-Wohl D, Hurwitz A, Haimov-Kochman R, Yagel S \& Imbar T 2017 Elevated circulating micro-ribonucleic acid (miRNA)-200b and miRNA-429 levels in anovulatory women. Fertility and Sterility 107 269-275. (https://doi.org/10.1016/j. fertnstert.2016.10.003)

FDA 2001 Safety Assessment of Di(2-Ethylhexyl)Phthalate (DEHP) Released from PVC Medical Devices. Rockville, MD, USA: Center for Devices and Radiological Health, United States Food and Drug Administration.

Fenner-Crisp PA, Maciorowski AF \& Timm GE 2000 The endocrine disruptor screening program developed by the U.S. Environmental Protection Agency. Ecotoxicology 9 85-91. (https://doi. org/10.1023/A:1008972330318)

Fernandez PC, Frank SR, Wang L, Schroeder M, Liu S, Greene J, Cocito A \& Amati B 2003 Genomic targets of the human c-Myc protein. Genes and Development 17 1115-1129. (https://doi.org/10.1101/ gad.1067003)

Gad SC, Spainhour CB, Shoemake C, Pallman DR, Stricker-Krongrad A, Downing PA, Seals RE, Eagle LA, Polhamus K \& Daly J 2016 Tolerable levels of nonclinical vehicles and formulations used in studies by multiple routes in multiple species With notes on methods to improve utility. International Journal of Toxicology $\mathbf{3 5}$ 95-178. (https://doi.org/10.1177/1091581815622442)

Gaido KW, Hensley JB, Liu D, Wallace DG, Borghoff S, Johnson KJ, Hall SJ \& Boekelheide K 2007 Fetal mouse phthalate exposure shows that gonocyte multinucleation is not associated with decreased testicular testosterone. Toxicological Sciences 97 491-503. (https://doi. org/10.1093/toxsci/kfm049)

Garcia-Lopez J, Brieno-Enriquez MA \& Del Mazo J 2013 MicroRNA biogenesis and variability. Biomolecular Concepts 4 367-380. (https:// doi.org/10.1515/bmc-2013-0015)

Gavin DP \& Akbarian S 2012 Epigenetic and post-transcriptional dysregulation of gene expression in schizophrenia and related 
disease. Neurobiology of Disease 46 255-262. (https://doi. org/10.1016/j.nbd.2011.12.008)

Gleicher N, Weghofer A \& Barad DH 2011 The role of androgens in follicle maturation and ovulation induction: friend or foe of infertility treatment? Reproductive Biology and Endocrinology 9116. (https://doi.org/10.1186/1477-7827-9-116)

Guart A, Bono-Blay F, Borrell A \& Lacorte S 2011 Migration of plasticizers phthalates, bisphenol A and alkylphenols from plastic containers and evaluation of risk. Food Additives and Contaminants: Part A, Chemistry, Analysis, Control, Exposure and Risk Assessment 28 676-685. (https://doi.org/10.1080/19440049.2011.555845)

Guo Y, Sun J \& Lai D 2017 Role of microRNAs in premature ovarian insufficiency. Reproductive Biology and Endocrinology 15 38. (https:// doi.org/10.1186/s12958-017-0256-3)

Hannon PR \& Flaws JA 2015 The effects of phthalates on the ovary. Frontiers in Endocrinology 6 8. (https://doi.org/10.3389/ fendo.2015.00008)

He T, Sun Y, Zhang Y, Zhao S, Zheng Y, Hao G \& Shi Y 2019 MicroRNA200b and microRNA-200c are up-regulated in PCOS granulosa cell and inhibit KGN cell proliferation via targeting PTEN. Reproductive Biology and Endocrinology 17 68. (https://doi.org/10.1186/s12958-0190505-8)

Hines CJ, Hopf NB, Deddens JA, Silva MJ \& Calafat AM 2011 Estimated daily intake of phthalates in occupationally exposed groups. Journal of Exposure Science and Environmental Epidemiology 21 133-141. (https://doi.org/10.1038/jes.2009.62)

Hseu YC, Hsu TW, Lin HD, Chen CH \& Chen SC 2017 Molecular mechanisms of discrotophos-induced toxicity in HepG2 cells: the role of CSA in oxidative stress. Food and Chemical Toxicology 103 253-260. (https://doi.org/10.1016/j.fct.2017.03.023)

Huang X, Liu C, Hao C, Tang Q, Liu R, Lin S, Zhang L \& Yan W 2016 Identification of altered microRNAs and mRNAs in the cumulus cells of PCOS patients: miRNA-509-3p promotes oestradiol secretion by targeting MAP3K8. Reproduction 151 643-655. (https://doi. org/10.1530/REP-16-0071)

Hwang K-A \& Choi K-C 2015 Chapter one - Endocrine-disrupting chemicals with estrogenicity posing the risk of cancer progression in estrogen-responsive organs. In Advances in Molecular Toxicology, pp. 1-33. Eds JC Fishbein \& JM Heilman. Amsterdam, Netherlands: Elsevier.

Jennen DG, Magkoufopoulou C, Ketelslegers HB, van Herwijnen MH, Kleinjans JC \& van Delft JH 2010 Comparison of HepG2 and HepaRG by whole-genome gene expression analysis for the purpose of chemical hazard identification. Toxicological Sciences 115 66-79. (https://doi.org/10.1093/toxsci/kfq026)

Jonsson B 2006 Risk Assesment on Butylphenol, Octylphenol and Nonylphenol, and Estimated Human Exposure of Alkylphenols from Swedish Fish, in Department of Physiology and Developmental Biology. Uppsala, Sweden: Environmental Toxicology, Uppsala Universitet.

Kavlock R, Boekelheide K, Chapin R, Cunningham M, Faustman E, Foster P, Golub M, Henderson R, Hinberg I, Little R, et al. 2002 NTP Center for the evaluation of risks to human reproduction: phthalates expert panel report on the reproductive and developmental toxicity of di(2-ethylhexyl) phthalate. Reproductive Toxicology 16 529-653. (https://doi.org/10.1016/S0890-6238(02)00032-1)

Kavlock R, Barr D, Boekelheide K, Breslin W, Breysse P, Chapin R, Gaido K, Hodgson E, Marcus M, Shea K, et al. 2006 NTP-CERHR expert panel update on the reproductive and developmental toxicity of di(2-ethylhexyl) phthalate. Reproductive Toxicology 22 291-399. (https://doi.org/10.1016/j.reprotox.2006.04.007)

Kim B, Ha M, Loeff L, Chang H, Simanshu DK, Li S, Fareh M, Patel DJ, Joo C \& Kim VN 2015 TUT7 controls the fate of precursor microRNAs by using three different uridylation mechanisms. EMBO Journal 34 1801-1815. (https://doi.org/10.15252/embj.201590931)

Kim YS, Kim HR, Kim H, Yang SC, Park M, Yoon JA, Lim HJ, Hong SH, DeMayo FJ, Lydon JP, et al. 2016 Deficiency in DGCR8-dependent canonical microRNAs causes infertility due to multiple abnormalities during uterine development in mice. Scientific Reports 620242. (https://doi.org/10.1038/srep20242)

Kostka G, Urbanek-Olejnik K \& Wiadrowska B 2010 Di-butyl phthalateinduced hypomethylation of the c-myc gene in rat liver. Toxicology and Industrial Health 26 407-416. (https://doi. org/10.1177/0748233710369124)

Kuang H, Han D, Xie J, Yan Y, Li J \& Ge P 2014 Profiling of differentially expressed microRNAs in premature ovarian failure in an animal model. Gynecological Endocrinology 30 57-61. (https://doi. org/10.3109/09513590.2013.850659)

Kurzynska-Kokorniak A, Koralewska N, Pokornowska M, Urbanowicz A, Tworak A, Mickiewicz A \& Figlerowicz M 2015 The many faces of Dicer: the complexity of the mechanisms regulating Dicer gene expression and enzyme activities. Nucleic Acids Research $\mathbf{4 3}$ 4365-4380. (https://doi.org/10.1093/nar/gkv328)

Laifenfeld D, Qiu L, Swiss R, Park J, Macoritto M, Will Y, Younis HS \& Lawton M 2014 Utilization of causal reasoning of hepatic gene expression in rats to identify molecular pathways of idiosyncratic drug-induced liver injury. Toxicological Sciences 137 234-248. (https://doi.org/10.1093/toxsci/kft232)

Lawson C, Gieske M, Murdoch B, Ye P, Li Y, Hassold T \& Hunt PA 2011 Gene expression in the fetal mouse ovary is altered by exposure to low doses of bisphenol A. Biology of Reproduction 84 79-86. (https:// doi.org/10.1095/biolreprod.110.084814)

Lei L, Jin S, Gonzalez G, Behringer RR \& Woodruff TK 2010 The regulatory role of Dicer in folliculogenesis in mice. Molecular and Cellular Endocrinology 315 63-73. (https://doi.org/10.1016/j.mce.2009.09.021)

Leung JY, Ehmann GL, Giangrande PH \& Nevins JR 2008 A role for Myc in facilitating transcription activation by E2F1. Oncogene $\mathbf{2 7}$ 4172-4179. (https://doi.org/10.1038/onc.2008.55)

Li Y, Fang Y, Liu Y \& Yang X 2015 MicroRNAs in ovarian function and disorders. Journal of Ovarian Research 8 51. (https://doi.org/10.1186/ s13048-015-0162-2)

Li L, Liu JC, Lai FN, Liu HQ, Zhang XF, Dyce PW, Shen W \& Chen H $2016 \mathrm{Di}$ (2-ethylhexyl) phthalate exposure impairs growth of antral follicle in mice. PLoS ONE 11 e0148350. (https://doi.org/10.1371/ journal.pone.0148350)

Liang Y, Ridzon D, Wong L \& Chen C 2007 Characterization of microRNA expression profiles in normal human tissues. BMC Genomics 8 166. (https://doi.org/10.1186/1471-2164-8-166)

Lin Y, Ding D, Huang Q, Liu Q, Lu H, Lu Y, Chi Y, Sun X, Ye G, Zhu H, et al. 2017 Downregulation of miR-192 causes hepatic steatosis and lipid accumulation by inducing SREBF1: novel mechanism for bisphenol A-triggered non-alcoholic fatty liver disease. Biochimica et Biophysica Acta: Molecular and Cell Biology of Lipids 1862 869-882. (https://doi.org/10.1016/j.bbalip.2017.05.001)

Lite C, Ahmed SSSJ, Santosh W \& Seetharaman B 2019 Prenatal exposure to bisphenol-A altered miRNA-224 and protein expression of aromatase in ovarian granulosa cells concomitant with elevated serum estradiol levels in F1 adult offspring. Journal of Biochemical and Molecular Toxicology 33 e22317. (https://doi.org/10.1002/jbt.22317)

Liu J, Wang W, Zhu J, Li Y, Luo L, Huang Y \& Zhang W 2018 Di(2ethylhexyl) phthalate (DEHP) influences follicular development in mice between the weaning period and maturity by interfering with ovarian development factors and microRNAs. Environmental Toxicology 33 535-544. (https://doi.org/10.1002/tox.22540)

Lü B, Jiang L-f \& Zhan P 2010 Effects of nonylphenol on ovarian cancer cells PEO4 c-myc and p53 mRNA and protein expression. Toxicological and Environmental Chemistry 92 1303-1308. (https://doi. org/10.1080/02772240903503906)

Luu BE, Green SR, Childers CL, Holahan MR \& Storey KB 2017 The roles of hippocampal microRNAs in response to acute postnatal exposure to di(2-ethylhexyl) phthalate in female and male rats. Neurotoxicology 59 98-104. (https://doi.org/10.1016/j. neuro.2017.02.004) 
Lykke-Andersen K, Gilchrist MJ, Grabarek JB, Das P, Miska E \& ZernickaGoetz M 2008 Maternal argonaute 2 is essential for early mouse development at the maternal-zygotic transition. Molecular Biology of the Cell 19 4383-4392. (https://doi.org/10.1091/mbc.e08-02-0219)

Magkoufopoulou C, Claessen SM, Jennen DG, Kleinjans JC \& van Delft JH 2011 Comparison of phenotypic and transcriptomic effects of false-positive genotoxins, true genotoxins and non-genotoxins using HepG2 cells. Mutagenesis 26 593-604. (https://doi.org/10.1093/ mutage/ger021)

Mahemuti L, Chen Q, Coughlan MC, Qiao C, Chepelev NL, Florian M, Dong D, Woodworth RG, Yan J, Cao XL, et al. 2018 Bisphenol A induces DSB-ATM-p53 signaling leading to cell cycle arrest, senescence, autophagy, stress response, and estrogen release in human fetal lung fibroblasts. Archives of Toxicology 92 1453-1469. (https://doi.org/10.1007/s00204-017-2150-3)

Martinez RM, Hauser R, Liang L, Mansur A, Adir M, Dioni L, Racowsky C, Bollati V, Baccarelli AA \& Machtinger R 2019 Urinary concentrations of phenols and phthalate metabolites reflect extracellular vesicle microRNA expression in follicular fluid. Environment International 123 20-28. (https://doi.org/10.1016/j. envint.2018.11.043)

McBride D, Carre W, Sontakke SD, Hogg CO, Law A, Donadeu FX \& Clinton M 2012 Identification of miRNAs associated with the follicular-luteal transition in the ruminant ovary. Reproduction $\mathbf{1 4 4}$ 221-233. (https://doi.org/10.1530/REP-12-0025)

Messerlian C, Souter I, Gaskins AJ, Williams PL, Ford JB, Chiu YH, Calafat AM, Hauser R \& Earth Study Team 2016 Urinary phthalate metabolites and ovarian reserve among women seeking infertility care. Human Reproduction 31 75-83. (https://doi.org/10.1093/ humrep/dev292)

Mitro SD, Dodson RE, Singla V, Adamkiewicz G, Elmi AF, Tilly MK \& Zota AR 2016 Consumer product chemicals in indoor dust: a quantitative meta-analysis of U.S. studies. Environmental Science and Technology 50 10661-10672. (https://doi.org/10.1021/acs.est.6b02023)

Nagaraja AK, Andreu-Vieyra C, Franco HL, Ma L, Chen R, Han DY, Zhu H, Agno JE, Gunaratne PH, DeMayo FJ, et al. 2008 Deletion of Dicer in somatic cells of the female reproductive tract causes sterility. Molecular Endocrinology 22 2336-2352. (https://doi.org/10.1210/ me.2008-0142)

Nayak S, Ren Y \& Rajkovic A 2016 The rise and fall of oogonial stem cells within the historical context of adult stem cells. In Primary Ovarian Insufficiency: A Clinical Guide to Early Menopause, pp. 159-177. Eds NF Santoro \& AR Cooper. Cham, Switzerland: Springer International Publishing.

NTP-CERHR 2003a NTP-CERHR monograph on the potential human reproductive and developmental effects of butyl benzyl phthalate (BBP). In NTP CERHR MON (5), i-III90. Research Triangle Park, NC, USA: National Toxicology Program. (available at: http://www.ncbi. nlm.nih.gov/pubmed/15995737)

NTP-CERHR $2003 b$ NTP-CERHR monograph on the potential human reproductive and developmental effects of di-n-butyl phthalate (DBP). In NTP CERHR MON (4), i-III90. Research Triangle Park, NC, USA: National Toxicology Program. (available at: http://www.ncbi. nlm.nih.gov/pubmed/15995736)

Osimitz TG, Droege W \& Driver JH 2015 Human risk assessment for nonylphenol. Human and Ecological Risk Assessment: an International Journal 21 1903-1919. (https://doi. org/10.1080/10807039.2014.999520)

Otsuka M, Zheng M, Hayashi M, Lee JD, Yoshino O, Lin S \& Han J 2008 Impaired microRNA processing causes corpus luteum insufficiency and infertility in mice. Journal of Clinical Investigation $\mathbf{1 1 8}$ 1944-1954. (https://doi.org/10.1172/JCI33680)

Pan B, Toms D, Shen W \& Li J 2015 MicroRNA-378 regulates oocyte maturation via the suppression of aromatase in porcine cumulus cells. American Journal of Physiology: Endocrinology and Metabolism 308 E525-E534. (https://doi.org/10.1152/ajpendo.00480.2014)
Parikh FR, Uttamchandani S, Velumani AS, Athalye A, Sinkar P, Naik N, Khandare P \& Velumani A 2018 Higher follicular fluid (FF) levels of di(2-ethylhexyl) phthalate (DEHP) metabolites in Indian women with poor ovarian reserve (POR). Fertility and Sterility 110 e170-e171. (https://doi.org/10.1016/j.fertnstert.2018.07.506)

Patino-Garcia D, Cruz-Fernandes L, Bunay J, Palomino J \& Moreno RD 2018 Reproductive alterations in chronically exposed female mice to environmentally relevant doses of a mixture of phthalates and alkylphenols. Endocrinology 159 1050-1061. (https://doi.org/10.1210/ en.2017-00614)

Patino-Garcia D, Rocha-Perez N, Moreno RD \& Orellana R 2019 Antigen retrieval by citrate solution improves western blot signal. MethodsX $\mathbf{6}$ 464-468. (https://doi.org/10.1016/j.mex.2019.02.030)

Qi X, Yang X, Chen S, Xiaoyun H, Dweep H, Guo M, Cheng W-H, Xu W-T, Luo Y \& Gretz N 2014 Ochratoxin A induced early hepatotoxicity: new mechanistic insights from microRNA, mRNA and proteomic profiling studies. Scientific Reports 4 5163. (https://doi. org/10.1038/srep05163)

Sanchez F \& Smitz J 2012 Molecular control of oogenesis. Biochimica et Biophysica Acta 1822 1896-1912. (https://doi.org/10.1016/j. bbadis.2012.05.013)

Sandhu R, Rivenbark AG \& Coleman WB 2012 Loss of posttranscriptional regulation of DNMT3b by microRNAs: a possible molecular mechanism for the hypermethylation defect observed in a subset of breast cancer cell lines. International Journal of Oncology $\mathbf{4 1}$ 721-732. (https://doi.org/10.3892/ijo.2012.1505)

Sang Q, Yao Z, Wang H, Feng R, Wang H, Zhao X, Xing Q, Jin L, He L, Wu L, et al. 2013 Identification of microRNAs in human follicular fluid: characterization of microRNAs that govern steroidogenesis in vitro and are associated with polycystic ovary syndrome in vivo. Journal of Clinical Endocrinology and Metabolism 98 3068-3079. (https://doi.org/10.1210/jc.2013-1715)

Sathyanarayana S, Butts S, Wang C, Barrett E, Nguyen R, Schwartz SM, Haaland W, Swan SH \& TIDES Team 2017 Early prenatal phthalate exposure, sex steroid hormones, and birth outcomes. Journal of Clinical Endocrinology and Metabolism 102 1870-1878. (https://doi. org/10.1210/jc.2016-3837)

Senfter D, Madlener S, Krupitza G \& Mader RM 2016 The microRNA-200 family: still much to discover. Biomolecular Concepts 7 311-319. (https://doi.org/10.1515/bmc-2016-0020)

Shelby MD 2006 NTP-CERHR monograph on the potential human reproductive and developmental effects of di (2-ethylhexyl) phthalate (DEHP). In NTP CERHR MON (18), v, vii-7, II-iii-xiii passim. Research Triangle Park, NC, USA: National Toxicology Program. (available at: http://www.ncbi.nlm.nih.gov/pubmed/19407857)

Snedeker SM \& Hay AG 2014 The alkylphenols nonylphenol and octylphenol in food contact materials and household items: exposure and health risk considerations. In Toxicants in Food Packaging and Household Plastics: Exposure and Health Risks to Consumers, pp. 125-150. Ed SM Snedeker. London, UK: Springer.

Somasundaram DB, Manokaran K, Selvanesan BC \& Bhaskaran RS 2017 Impact of di-(2-ethylhexyl)phthalate on the uterus of adult Wistar rats. Human and Experimental Toxicology 36 565-572. (https://doi. org/10.1177/0960327116657601)

Spangenberg E, Wallenbeck A, Eklöf AC, Carlstedt-Duke J \& Tjäder S 2014 Housing breeding mice in three different IVC systems: maternal performance and pup development. Laboratory Animals $\mathbf{4 8}$ 193-206. (https://doi.org/10.1177/0023677214531569)

Tait S, Tassinari R, Maranghi F \& Mantovani A 2015 Bisphenol A affects placental layers morphology and angiogenesis during early pregnancy phase in mice. Journal of Applied Toxicology 35 1278-1291. (https://doi.org/10.1002/jat.3176)

Thomas FH, Walters KA \& Telfer EE 2003 How to make a good oocyte: an update on in-vitro models to study follicle regulation. Human Reproduction Update 9 541-555. (https://doi.org/10.1093/humupd/ dmg042) 
Toms D, Pan B \& Li J 2017 Endocrine regulation in the ovary by microRNA during the estrous cycle. Frontiers in Endocrinology 8378. (https://doi.org/10.3389/fendo.2017.00378)

Tranfo G, Caporossi L, Paci E, Aragona C, Romanzi D, De Carolis C, De Rosa M, Capanna S, Papaleo B \& Pera A 2012 Urinary phthalate monoesters concentration in couples with infertility problems. Toxicology Letters 213 15-20. (https://doi.org/10.1016/j. toxlet.2011.11.033)

Uzumcu M, Zama AM \& Oruc E 2012 Epigenetic mechanisms in the actions of endocrine-disrupting chemicals: gonadal effects and role in female reproduction. Reproduction in Domestic Animals 47 (Supplement 4) 338-347. (https://doi. org/10.1111/j.1439-0531.2012.02096.x)

Wang X, Zhao X, Gao P \& Wu M 2013 c-Myc modulates microRNA processing via the transcriptional regulation of Drosha. Scientific Reports 3 1942. (https://doi.org/10.1038/srep01942)

Willoughby KN, Sarkar AJ, Boyadjieva NI \& Sarkar DK 2005 Neonatally administered tert-octylphenol affects onset of puberty and reproductive development in female rats. Endocrine 26 161-168. (https://doi.org/10.1385/ENDO:26:2:161)

Wood MA \& Rajkovic A 2013 Genomic markers of ovarian reserve. Seminars in Reproductive Medicine 31 399-415. (https://doi. org/10.1055/s-0033-1356476)

Xu S, Linher-Melville K, Yang BB, Wu D \& Li J 2011 Micro-RNA378 (miR-378) regulates ovarian estradiol production by targeting aromatase. Endocrinology 152 3941-3951. (https://doi.org/10.1210/ en.2011-1147)
Xue Y, Lv J, Xu P, Gu L, Cao J, Xu L, Xue K \& Li Q 2018 Identification of microRNAs and genes associated with hyperandrogenism in the follicular fluid of women with polycystic ovary syndrome. Journal of Cellular Biochemistry 119 3913-3921. (https://doi.org/10.1002/jcb.26531)

Yang S, Wang S, Luo A, Ding T, Lai Z, Shen W, Ma X, Cao C, Shi L, Jiang J, et al. 2013 Expression patterns and regulatory functions of microRNAs during the initiation of primordial follicle development in the neonatal mouse ovary. Biology of Reproduction 89 126. (https:// doi.org/10.1095/biolreprod.113.107730)

Ye W, Lv Q, Wong CK, Hu S, Fu C, Hua Z, Cai G, Li G, Yang BB \& Zhang Y 2008 The effect of central loops in miRNA:MRE duplexes on the efficiency of miRNA-mediated gene regulation. PLOS ONE 3 e1719. (https://doi.org/10.1371/journal.pone.0001719)

Young JM \& McNeilly AS 2010 Theca: the forgotten cell of the ovarian follicle. Reproduction 140 489-504. (https://doi. org/10.1530/REP-10-0094)

Yuan S, Ortogero N, Wu Q, Zheng H \& Yan W 2014 Murine follicular development requires oocyte DICER, but not DROSHA. Biology of Reproduction 91 39. (https://doi.org/10.1095/biolreprod.114.119370)

Zhang JN, Zhang RQ, Liu JC, Li L, Shen W \& Sun XF 2019 Di(2ethylhexyl)phthalate exposure impairs the microRNAs expression profile during primordial follicle assembly. Frontiers in Endocrinology 10 877. (https://doi.org/10.3389/fendo.2019.00877)

Zou X, Lu T, Zhao Z, Liu G, Lian Z, Guo Y, Sun B, Liu D \& Li Y 2020 Comprehensive analysis of mRNAs and miRNAs in the ovarian follicles of uniparous and multiple goats at estrus phase. BMC Genomics 21 267. (https://doi.org/10.1186/s12864-020-6671-4)

Received in final form 17 September 2020

Accepted 28 September 2020

Accepted Manuscript published online 29 September 2020
(C) 2020 Society for Endocrinology Published by Bioscientifica Ltd. Printed in Great Britain 